\title{
REPRESENTAÇÕES SOCIAIS DO PROCESSO DE ENVELHECIMENTO DE PACIENTES PSIQUIÁTRICOS INSTITUCIONALIZADOS
}

\author{
Social representations of aging in institutionalized psychiatric patients. \\ Representaciones sociales del envejecimiento de los pacientes psiquiátricos \\ institucionalizados.
}

Leandro Andrade da Silva ${ }^{1}$

Antônio Marcos Tosoli Gomes²

Denize Cristina de Oliveira ${ }^{3}$

Maria das Graças Gazel de Souza ${ }^{4}$

\section{RESUMO}

Esta pesquisa objetivou analisar a representação social do processo de envelhecimento de pacientes psiquiátricos institucionalizados para profissionais de saúde. Trata-se de um estudo qualitativo, desenvolvido com a abordagem estrutural das representações sociais, realizada em dois macro-hospitais do Rio de Janeiro, com 50 profissionais de saúde. Realizou-se a coleta de dados através da técnica de evocações livres e a análise com o software EVOC - Ensemble de Programmes Permettant L'analyse des Évocations. Foram evocadas 250 palavras em resposta ao termo indutor Envelhecer em Psiquiatria/Saúde Mental, que foram agrupadas em 3 dimensões, quais sejam, afetivo/emocional, exclusão/abandono e assistencial/institucional. 0 grupo explicitou, no bojo de sua representação, que o fenômeno envelhecimento dos pacientes com adoecimento mental em um ambiente institucional fechado e recluso é reconstituído como permeado por uma afetividade caracteristicamente negativa, possivelmente como consequência das demais dimensões presentes no núcleo central da representação, especialmente exclusão e abandono familiar, social, público e institucional.

Palavras-chave: Envelhecimento. Assistência de Longa Duração. Saúde Mental. Enfermagem Psiquiátrica.

\begin{abstract}
This study aimed to analyze the social representation of aging in institutionalized psychiatric patients to health professionals. This is a qualitative study was developed with the contribution of the structural approach of social representations theory, held on two macro-hospitals located in Rio de Janeiro, attended by 50 health professionals. We performed data collection using the technique of evocation and analysis with free software Ensemble de Programmes Permettant L'analyse des Évocations (EVOC). 250 words evoked in response to the inductive term aging, Psychiatric / Mental Health, grouped into three dimensions, namely, affective / emotional, exclusion and abandonment and care / institutional. The group explained, in the midst of its representation, that the phenomenon of aging patients with mental illness in an institutional environment is closed and reclusive reconstituted as pervaded by a distinctively negative affectivity, possibly as a consequence of other dimensions in the core of representation, especially exclusion and family abandonment, social, and public institution.
\end{abstract}

Keywords: Aging. Long-Term Care. Mental Health. Psychiatric Nursing.

\section{Resumen}

El objetivo de la investigación fue analizar la representación social del envejecimiento en los pacientes psiquiátricos institucionalizados para profesionales de salud. El estudio cualitativo, desarrollado con la contribución del enfoque estructural de la teoría de las representaciones sociales, se celebró en dos grandes hospitales de la ciudad de Rio de Janeiro, al que asistieron 50 profesionales de la salud. La recolección de datos utilizó la técnica de evocación libre y el análisis con el software EVOC - Ensemble de Programmes Permettant L'analyse des Évocations. Fueran evocadas 250 palabras en respuesta al termo inductor Envejecer en Psiquiatría / Salud Mental, puesto en tres dimensiones: afectivo/emocional; exclusión/abandono; atención/institucional. El grupo explicó, en su representación, que el fenómeno de los pacientes ancianos con enfermedad mental en un ambiente institucional cerrado y recluso, reconstituido y compuesto por una afectividad considerada negativa, es una posible consecuencia de otras dimensiones en el núcleo de la representación, especialmente por la exclusión y el desinterés familiar, social, gubernamental e institucional.

Palabras Clave: Envejecimiento. Cuidados a Largo Plazo. Salud Mental. Enfermería Psiquiátrica.

'Enfermeiro; Mestrando em Enfermagem pela Universidade do Estado do Rio de Janeiro - UERJ; Bolsista da Coordenação de Aperfeiçoamento de Pessoal de Nível Superior - CAPES; Membro do Grupo de Pesquisa Promoção da Saúde e Práticas de Cuidado de Enfermagem e Saúde de Grupos Populacionais - UERJ. Rio de Janeiro-RJ. Brasil. E-mail: leandrotorj@yahoo.com.br, ${ }^{2}$ Enfermeiro; Doutor em Enfermagem pela Escola de Enfermagem Anna Nery da Universidade Federal do Rio de Janeiro EEAN-UFRJ; Professor do Programa de Pós-Graduação em Enfermagem e do Departamento de Enfermagem Médico Cirúrgico da Faculdade de Enfermagem da Universidade do Estado do Rio de Janeiro - UERJ. Rio de Janeiro-RJ. Brasil. E-mail: mtosoli@gmail.com, ${ }^{3}$ Pós-Doutora pela École des Hautes Études en Sciences Sociales - EHESS, França; Doutora em Saúde Pública pela Universidade de São Paulo - USP; Professora do Programa de Pós-Graduação em Enfermagem e do Departamento de Fundamentos de Enfermagem da Faculdade de Enfermagem da Universidade do Estado do Rio de Janeiro - UERJ. Rio de Janeiro-RJ. Brasil. E-mail: dcouerj@gmail.com, ${ }^{4}$ Enfermeira; Mestranda em Enfermagem pela Universidade do Estado do Rio de Janeiro - UERJ; Enfermeira do Setor de Onco-Hematologia do Instituto Nacional de Câncer - INCA. Rio de Janeiro-RJ. Brasil. E-mail: mariagazel@bol.com.br 


\section{INTRODUÇ̃̃O}

Há algumas décadas as questões relacionadas ao envelhecimento e à longevidade humana vêm sendo discutidas nos meios acadêmicos e científicos. 0 Brasil tem acompanhado esta tendência quando se observa o aumento da expectativa de vida de sua população que, por sua vez, pode ser atribuído a diversos fatores, como os avanços das ciências da saúde, a melhoria do saneamento ambiental e a novas formas de organização familiar, social, cultural, econômica e política presentes na contemporaneidade.

A Organização Mundial da Saúde ${ }^{1}$ (OMS) define a população idosa através de uma distinção relacionada aos países. Naqueles considerados desenvolvidos, classifica-se como idoso o sujeito a partir dos 60 anos de idade, enquanto nos em desenvolvimento, este valor sobe para 65 anos. ${ }^{2} \mathrm{Em}$ âmbito nacional, a Lei $10.471 / 03^{3}$ que dispõe sobre o Estatuto da Pessoa ldosa, define o idoso como sendo a pessoa acima de 60 anos de idade, em conformidade com a recomendação da OMS.

0 envelhecimento populacional tem apresentado desafios a serem enfrentados pela sociedade e pelas políticas públicas. A proporção mundial de pessoas com 60 anos ou mais cresce de forma mais rápida que a de outras faixas etárias. Acredita-se que até 0 ano 2050 haja dois bilhões de idosos, $80 \%$ deles nos países em desenvolvimento. ${ }^{4}$ Neste sentido, a população idosa brasileira configura um contingente de quase 15 milhões de pessoas, representando 8,6\% da população total do País?

Este artigo propõe-se a discutir uma temática específica e pouco explorada, qual seja, a representação social dos profissionais de saúde mental acerca do processo de envelhecimento de pacientes internados em instituições psiquiátricas, com características asilares. Serão tomadas em foco as pessoas idosas internadas há muitos anos nestes locais. Durante séculos a reclusão social foi considerada uma maneira de tratar as psicopatologias, e a internação foi o modelo basilar adotado para se intervir junto à loucura. Ao longo de anos, crianças, jovens e adultos jovens foram internados em hospitais psiquiátricos, espaços nos quais a abordagem sobre o individual dava espaço ao coletivo. Nos manicômios, todos os internos deveriam usar uniformes, seguir rotinas para as alimentações; para a higienização, incluía-se também a obediência ao toque de recolher, entre outras atitudes que imprimiam a descaracterização do ser e de sua identidade.

Nos últimos 30 anos, o Brasil instituiu políticas para a desativação de leitos psiquiátricos, ${ }^{5}$ fazendo, em paralelo, a substituição de modelos manicomiais por uma rede alternativa e territorializada de serviços. Tais ações foram constituídas a partir da estratégia de desinstitucionalização de uma clientela de longa permanência institucional. A reabilitação psicossocial de pacientes crônicos internados por muitos anos perpassa por intervenções que envolvem diversos atores sociais, bem como a reconstrução de territórios, englobando as singularidades e as subjetividades de um mundo a ser vivido fora do âmbito hospitalar. ${ }^{6}$

Em um levantamento realizado pelo Ministério da Saúde a partir de dados do Programa Nacional de Avaliação do Sistema Hospitalar/Psiquiatria ${ }^{7}$ (PNASH/Psiquiatria), em 1996 existiam 72.514 leitos psiquiátricos no país, reduzidos para 39.567 leitos em 2006; 62\% dos hospitais apresentavam $20 \%$ ou mais de pacientes de longa permanência, revelando um porcentual de residentes em hospitais psiquiátricos em Estados como a Bahia, de 25,6\%. Já em São Paulo, quase $60 \%$ e, no Rio de Janeiro, entre 40 e 50\%. Como índice aproximado para fins de planejamento, podemos considerar que $35 \%$ dos pacientes residem em hospitais conveniados ao Sistema Único de Saúde (SUS) e que a região Sudeste concentra a maior parte dos leitos, $60,32 \%$, indicando a necessidade de maiores intervenções para a desinstitucionalização dessa clientela. $^{7}$

Entretanto, de acordo com o Sistema de Informações em Saúde Mental ${ }^{8}$ (SISME) da Secretaria Municipal de Saúde do Rio de Janeiro, no período compreendido entre janeiro de 2001 e abril de 2010, 1.703 pacientes permanecem internados há mais de cinco anos em hospitais da rede e conveniados ao SUS. Destes, 734 estão internados nos hospitais selecionados para a realização deste estudo. ${ }^{8}$

Os dados acima revelam a herança deixada por anos de uma assistência hospitalocêntrica, marcada pela reclusão e pela desfiliação social de um contingente de pacientes psiquiátricos que hoje são idosos.

Por desfiliação social compreende-se o processo de perdas de referencial, de identidade e de status social que, por sua vez, gera determinado grau de vulnerabilidade que é produzida pelo entrecruzamento de dois eixos, o da integração ou não integração através do trabalho, e o da inserção ou não em uma sociabilidade sociofamiliar. ${ }^{10}$

A integração dos eixos forma as seguintes zonas em que os diferentes indivíduos podem se inserir: zona de integração, na qual existe um trabalho permanente e o indivíduo mobiliza suportes relacionais sólidos; zona de vulnerabilidade, onde há precariedade nas relações de trabalho e fragilidade nas relações sociais; a de desfiliação, interpretada como a ausência de trabalho que acarretaria o isolamento social; e, finalmente, a de assistência, destinada aos incapacitados e às pessoas que desenvolvem trabalho que carecem de uma forte inserção nos meios sociais. ${ }^{10}$

Pensar em uma proposta assistencial, à luz do conceito de desfiliação social para essa clientela é uma tarefa complexa, principalmente em função das características adquiridas por esses sujeitos ao longo do processo de institucionalização, nos quais a desterritorialização, a dependência institucional, a perda de vínculos sociais e familiares e a idade avançada contribuíram para tornar essa uma questão complexa. 
Esses pacientes, internados há muito tempo em instituições asilares do Município do Rio de Janeiro, envelheceram no espaço manicomial, tiveram o curso de suas vidas alterado em função de diferentes transtornos mentais, afetivos ou até mesmo sociais. Diante de tal fato, essa pesquisa objetiva analisar a representação social do processo de envelhecimento em psiquiatria/saúde mental para os profissionais de saúde.

\section{METODOLOGIA}

Trata-se de uma pesquisa qualitativa, na qual adotouse uma abordagem complementar à Teoria das Representações Sociais, qual seja, a Abordagem Estrutural, também conhecida como Teoria do Núcleo Central. ${ }^{11-12}$ Neste contexto, define-se representação social como produto e processo de uma atividade mental, através da qual um indivíduo ou um grupo reconstitui a realidade com a qual ele se confronta e para a qual ele atribui um significado específico. ${ }^{12}$ De acordo com a Teoria do Núcleo Central, a organização de uma representação social apresenta uma característica espećífica, a de ser organizada em torno de um núcleo central, constituído por um ou mais elementos que dão significado à representação, bem como fornecem um sentido fundamental e inflexível à mesma. ${ }^{11}$

A abordagem estrutural concebe uma representação como uma organização que é atravessada por diferentes dimensões. ${ }^{13}$ As representações sociais possibilitam que fenômenos da vida comum tornem-se observáveis diretamente, ou seja, reconstruídos à luz do conhecimento reificado. Elas consideram a diversidade dos sujeitos, suas atitudes e suas culturas, objetivando compreender como os indivíduos e os grupos podem construir um mundo estável e previsível a partir da diversidade. ${ }^{14}$

0 desenho metodológico envolveu dois macro-hospitais psiquiátricos localizados na cidade do Rio de Janeiro. 0 primeiro é um antigo hospital do Ministério da Saúde, construído em 1912, funcionando da década 20 à de 80, como destino final para pacientes considerados irrecuperáveis. Neste, a pesquisa desenvolveu-se nos Núcleos de Moradia Assistida, destinado a pacientes de ambos os sexos. 0 segundo hospital, construído em 1917, considerado em 1918 o primeiro ambulatório psiquiátrico da América Latina, objetivava realizar um trabalho de "aconselhamento genético" na tentativa de prevenir os distúrbios mentais. Nele os cenários escolhidos foram as enfermarias readaptadas à moradia de pacientes.

Os referidos hospitais sofreram, a partir de 1996, um processo de mudança de gestão através da municipalização dos serviços, em consonância ao Sistema Único de Saúde de descentralização política, técnica e administrativa, no qual novas relações passaram a ser estabelecidas entre os níveis central e o local. A escolha destes campos justifica-se por terem sido construídos no início do século XX como local destinado a pacientes com longo tempo de internação $0^{15} \mathrm{e}$, ainda, possuírem, em seu interior, pacientes com tempo médio de internação de 20 anos.
Os dados foram coletados no primeiro semestre de 2010, no qual foram selecionados 50 profissionais de saúde mental, destes 26 profissionais de nível superior e 24 de nível médio. Estabeleceu-se como critério de inclusão, vivência mínima de um ano em atividades assistenciais. 0 critério de exclusão foi o profissional estar desviado de função, realizando atividades administrativas.

A coleta de dados foi realizada através da técnica de evocações livres, que buscou apreender a percepção da realidade a partir de uma composição semântica preexistente, composição esta normalmente não só concreta, mas também imagética, organizada ao redor de alguns elementos simbólicos simples. ${ }^{11}$ Nesse sentido, a aplicação prática do teste consistiu em pedir aos sujeitos que associassem, livre e rapidamente, cinco palavras a partir da audição ou visualização de palavras indutoras ou expressões. ${ }^{16}$

Para o tratamento dos dados coletados foi utilizado o software EVOC - Ensemble de Programmes Permettant L'analyse des Évocations - versão 2003, que possibilitou efetuar a organização das palavras produzidas em função da hierarquia implícita à combinação da frequência com a ordem natural de evocação. A técnica de análise consiste na construção de um quadro de quatro casas, pelas quais são distribuídas as palavras evocadas, considerando os critérios de maiores frequências e Ordens Médias de Evocação (OME). ${ }^{17}$

A análise dos dados consistiu em captar o sistema de categorização utilizado pelos sujeitos, permitindo 0 levantamento dos conteúdos da representação social. 0 tratamento dos dados evocados foi feito levando-se em consideração os critérios de frequência e ordem de aparição dos termos produzidos. As palavras que tiveram uma importância maior no esquema cognitivo dos sujeitos entrevistados foram aquelas indicativas de um possível núcleo central da representação social analisada. ${ }^{14-16}$

Segundo as premissas da Teoria do Núcleo Central, as palavras agrupadas no quadrante superior esquerdo, que possuíram as maiores frequências e foram as mais prontamente evocadas, formaram o núcleo central da representação social. ${ }^{16}$ 0 sistema periférico, por sua vez, localiza-se nos quadrantes superior e inferior direito, respectivamente primeira e segunda periferia. Os elementos de contraste encontraram-se no quadrante inferior esquerdo.

No tocante aos aspectos éticos da pesquisa, foram respeitados os princípios da Resolução 196/96 do Ministério da Saúde. 0 projeto foi aprovado pelo Comitê de Ética em Pesquisa - Conselhos Humanos do Instituto Municipal Philippe Pinel, sob o parecer № 53/2010 e pelo Comitê de Ética em Pesquisa do Instituto Municipal de Assistência à Saúde Juliano Moreira, sob o parecer 13/2009, ambos vinculados à Superintendência de Institutos Municipais da Sub-Secretaria de Apoio Hospitalar, Urgência e Emergência. Todos os participantes assinaram e receberam uma cópia do Termo de Consentimento Livre e Esclarecido. 


\section{ANÁLISE E DISCUSSÃO}

De modo a compreender melhor as representações sociais desenvolvidas pelos sujeitos do estudo, destaca-se que quase todos os profissionais, independente da idade ou de sua categoria, desenvolvem, ainda, hoje, atividades assistenciais, embora todos já tenham apresentado, em algum momento de suas carreiras, atividades gerenciais. Mais da metade dos indivíduos é integrante da equipe de enfermagem, seguida das demais categorias, como médicos, psicólogos e assistentes sociais, sendo que o grupo de entrevistados foi composto, majoritariamente, de profissionais de nível médio. Além dessas, ressalta-se também que as categorias de variável predominantes foram o sexo feminino, o estado civil casado e a religião católica.

A análise do corpus formado pelas evocações revelou que, em resposta ao termo indutor "Envelhecimento em Saúde Mental/Psiquiatria", foram evocadas 250 palavras, sendo a média da ordem média de evocações (rang) de 2,98; a frequência mínima, de 2; e a média, igual a 6,7. A análise combinada desses dados resultou no quadro de quatro casas apresentado na Tabela 1.

Tabela 1 - Quadro de quatro casas das evocações do termo indutor Envelhecimento em Saúde Mental .

\begin{tabular}{|c|c|c|c|c|c|c|c|c|}
\hline O.M.E. & $>2,7$ & & & & $<2,7$ & & & \\
\hline $\begin{array}{l}\text { Freq. } \\
\text { média }\end{array}$ & Termo evocado & Posição & Freq. & O.M.E. & $\begin{array}{c}\text { Termo } \\
\text { evocado }\end{array}$ & Posição & Freq. & O.M.E. \\
\hline \multirow[t]{5}{*}{$=7$} & Triste & - & 23 & 2,348 & $\begin{array}{l}\text { Sem- } \\
\text { referencial }\end{array}$ & - & 9 & 3,778 \\
\hline & Abandono & - & 17 & 2,765 & \multirow[t]{4}{*}{ Perdas } & \multirow[t]{4}{*}{-} & \multirow[t]{4}{*}{7} & \multirow[t]{4}{*}{3,714} \\
\hline & Solidão & - & 17 & 2,882 & & & & \\
\hline & Morte & - & 10 & 2,100 & & & & \\
\hline & Crônico & - & 8 & 2,875 & & & & \\
\hline \multirow[t]{14}{*}{$<2$} & Angustia & - & 6 & 2,500 & Vazio & - & 6 & 3,000 \\
\hline & Enlouquecedor & - & 3 & 2,000 & Carente & - & 6 & 3,500 \\
\hline & Depressão & - & 3 & 2,333 & Ruim & - & 5 & 3,200 \\
\hline & Institucionalização & - & 2 & 1,000 & Descaso & - & 4 & 3,000 \\
\hline & Sofrimento & - & 2 & 1,500 & Doença & - & 4 & 3,250 \\
\hline & \multirow[t]{9}{*}{ Afeto } & \multirow[t]{9}{*}{+} & \multirow[t]{9}{*}{2} & \multirow[t]{9}{*}{2,000} & & & & \\
\hline & & & & & Medo & - & 4 & 3,750 \\
\hline & & & & & Cuidado & - & 3 & 3,000 \\
\hline & & & & & Hospital & + & 3 & 3,000 \\
\hline & & & & & $\underline{\text { Isolado }}$ & - & 3 & 3,000 \\
\hline & & & & & Difícil & - & 3 & 4,333 \\
\hline & & & & & Rejeição & - & 3 & 3,667 \\
\hline & & & & & Saúde & - & 3 & 3,667 \\
\hline & & & & & & +- & & \\
\hline
\end{tabular}

Legenda: Negrito = Dimensão afetivo/emocional; Itálico = Dimensão exclusão/abandono; $\underline{\text { Sublinhado }}=$ assistencial/institucional.

Para melhor compreensão e síntese do quadro de quatro casas, as palavras evocadas foram classificadas em três dimensões, que organizam as representações do grupo estudado, quais sejam: afetivo/emocional, exclusão/abandono e assistencial/institucional, conforme legenda. Além dessas, parece estar se configurando uma dimensão avaliativa que já se encontra enraizada nos elementos de contraste, com desdobramentos no quadrante que se refere à segunda periferia. Observa-se, como será aprofundado na discussão desta última dimensão, que, apesar de sua não oposição aos elementos supostamente centrais, insere um elemento novo na representação profissional, que é a avaliação do processo de envelhecimento institucional de longa permanência dos pacientes psiquiátricos

Considerando as premissas da Teoria do Núcleo Central, as palavras agrupadas no quadrante superior esquerdo são aquelas que tiveram as maiores frequências e foram mais prontamente evocadas, formando, portanto, por hipótese, o núcleo central da representação social. Esses elementos caracterizam a parte mais consensual e estável da representação, assim como menos sensível a mudanças em função do contexto externo ou das práticas cotidianas dos sujeitos. ${ }^{12-14-16}$ 
A dimensão afetivo/emocional apresenta-se, no quadrante que alberga os elementos centrais, como aquela que possui a maior frequência (23) e o segundo menor rang através da palavra triste, seguida de solidão (frequência de 17 e rang 2,8). Esta dimensão desdobra-se, ainda, com marcante presença entre os elementos de contraste, através dos léxicos angústia (maior frequência do quadrante), sofrimento (segundo menor rang da análise), depressão e afeto. Mostra-se presente, ainda, na segunda periferia com as seguintes palavras: vazio (maior frequência e menor rang), medo e rejeição.

Diversos autores ${ }^{12-13-14-16}$ vêm pontuando a importância da afetividade nas representações em função desta característica humana se apresentar, entre outras coisas, como uma construção do grupo em que um indivíduo se insere e como um elemento que fornece sentido ao seu cotidiano. 0 grupo estudado explicita, no bojo de sua representação, que o fenômeno envelhecimento dos pacientes com adoecimento mental em um ambiente institucional fechado e recluso é reconstituído como sendo permeado por uma afetividade caracteristicamente negativa, possivelmente como consequência das demais dimensões presentes no núcleo central da representação em tela, especialmente a da exclusão e a do abandono familiar, social, público e institucional. Além disso, a dimensão afetiva é interpretada pelos sentimentos expressos pelos profissionais de saúde mental diante do processo de envelhecimento dos pacientes psiquiátricos institucionalizados com tempo de internação superior a 60 anos.

A negatividade característica desta dimensão nasce da experiência dos profissionais no cuidado constante prestado a esses pacientes e na observação dos seus sentimentos, reações e relações que são construídas e/ou rompidas ao longo das décadas de internação, traçando um modo próprio de ser e de se colocar perante o mundo e a sociedade. Trata-se de elementos representacionais que captam os sentimentos que caracterizam este processo no contexto em questão em que, em sua maioria, apresenta um rompimento de laços afetivos com o conjunto de pessoas importantes para os pacientes e suas histórias, como consideram determinados autores. ${ }^{4-5-6-15}$

No contexto desta dimensão, destaca-se, ainda, um elemento que se mostra como de contraste, afeto, que possui baixa frequência (apenas 2) e o terceiro menor rang de toda a análise (sendo evocado sempre na segunda posição). Em uma representação basicamente negativa, o elemento positivo pode estar determinado pelo relacionamento interpessoal entre 0 profissional e o paciente, do cuidado em saúde prestado por aquele a este e do reconhecimento das necessidades deste último em sua humanidade, a qual prevê a filiação dos indivíduos a grupos sociais que the confiram identidade e acolhida.

A aparição do termo afeto nessa posição do quadrante parece indicar uma dimensão avaliativa que já se encontra enraizada nos elementos de contraste. Observa-se que, apesar de sua não oposição aos elementos supostamente centrais, insere um elemento novo na representação profissional, que é a avaliação do processo de envelhecimento institucional de longa permanência dos pacientes psiquiátricos.

Com relação às duas palavras centrais nesta dimensão, os entrevistados justificaram que ambas mantêm forte relação entre si. Os sujeitos fizeram, durante o processo de coleta de dados, referencias à solidão como algo muito triste, questionando-se o quanto éintenso este sentimento no processo de envelhecer internado em um hospital psiquiátrico. Neste sentido, considera-se que, por mais que tenham ocorrido propostas de humanização do típico asilo psiquiátrico, este ainda mostra-se resultante de um modelo assistencial excludente que, na maioria das vezes, não atende às necessidades subjetivas dos indivíduos internados. ${ }^{5}$

A instituição da qual tratamos neste trabalho caracteriza-se como um local que possibilita o isolamento de grande número de indivíduos, separados da sociedade por considerável período de tempo e levados a uma vida fechada e formalmente administrada. Tais questionamentos não são contemporâneos, uma vez que, já em fins do século XIX, diversas críticas eram dirigidas a esse modelo. A principal fazia referência aos efeitos prejudiciais acarretados pela permanência prolongada em estabelecimentos psiquiátricos. Os pontos nevrálgicos baseavam-se (e ainda se baseiam) na hospitalização e no seu caráter segregador, com o agravamento ou a cronificação da doença, as características desumanizantes e despersonalizantes da instituição e o estigma gerado pela estadia no hospital psiquiátrico. ${ }^{15}$

Sobre o hospital psiquiátrico na década de 40, o Serviço de Terapêutica Ocupacional e Reabilitação (STOR) possibilitou uma revolução na assistência destinada a pacientes institucionalizados de longa internação. Nele procurava-se valorizar e divulgar a importância do componente afetivo, destacando, inclusive, que o acolhimento era o primeiro passo para o estabelecimento de um rapport terapêutico. Neste sentido, destaca-se que os pacientes conservam, mesmo depois de longos anos de internação, as ideias e os afetos dominantes durante todo o curso do processo psicótico e que, normalmente, derivam sempre das situações que absorviam o indivíduo antes da doença, como se o tempo parasse. ${ }^{18}$

A dimensão relativa à exclusão/abandono também se mostra transversal à estrutura da representação, com desdobramentos em todo o sistema periférico e caracterizandose por sua presença marcante na primeira periferia. No contexto dos possíveis elementos centrais, esta dimensão concretizase na palavra abandono, que, por sua importância, foi inserida na própria denominação da dimensão, mesmo que, em seus aspectos quantitativos (frequência 17 e rang 2,76), não apresente nenhum destaque quando comparada às demais.

A presença desta palavra é tida como algo corriqueiro no cenário manicomial, normalmente atrelada ao abandono familiar, como bem pontuam alguns autores. ${ }^{5-15-18}$ Para um grande número de pacientes é habitual o abandono por parte das famílias em seu processo de envelhecimento, inclusive com 
o fornecimento de endereços diferentes do real domicilio para não serem contatadas pelo hospital. ${ }^{15}$ Ao mesmo tempo, destaca-se a existência de casos nos quais os familiares, ao visitarem o paciente durante a internação, não se apresentarem como tais, a fim de não serem abordados por nenhum profissional da equipe de saúde. ${ }^{15}$ Outra tática destacada é a de visitar outro paciente da mesma enfermaria; durante este ato e de forma discreta, dirigirem-se ao leito do familiar internado, deixando biscoitos, cigarros, um par de chinelos debaixo do travesseiro, sem nenhuma exposição ou comprometimento familiar. ${ }^{15}$

Durante a história do adoecimento mental e de sua maior manifestação social, a loucura, o abandono tem sido uma das características do relacionamento entre a sociedade e os indivíduos acometidos por esta entidade mórbida. ${ }^{15}$ Quer seja por sua alteridade ou sua singularidade, por sua diferença comportamental e/ou social ou pela falta de adoção dos principais padrões culturais e sociais, a desfiliação familiar, cultural e social desses pacientes tem sido relatada de forma constante em diversas épocas e no contexto de diversas políticas de assistência à saúde. ${ }^{5}$

Na primeira periferia, esta dimensão apresenta-se desdobrada, de forma exclusiva, nas expressões sem referencial e perda que possuem, respectivamente, frequências de 9 e 7 , e rang de 3,77 e 3,71. Ressalta-se, no entanto, que, enquanto o termo sem referenciallimita-se à expressão em si mesma, 0 léxico perda teve, como sinônimos, as expressões perda do espaço, perda da identidade e perda total da identidade. Estas mostram, por sua vez e em maior grau, o poder do aparato institucional de produzir, nos pacientes internados por longos períodos de tempo, a cronificação de sua patologia e sucessivos processos de perdas de diferentes habilidades sociais, consideradas como um processo irreversível no campo de estudo das psicopatologias. ${ }^{15}$

A primeira periferia expõe uma estrutura representacional que explicita o processo de desfiliação social vivido pelos pacientes durante a sua vida pessoal e institucional e que se concretiza, de forma especial, em seu envelhecimento no espaço hospitalar. ${ }^{10-15}$ Neste processo, perdem-se as referências sociais e de pertença grupal externas à instituição em que se vive, tornando-o com chances cada vez mais reduzidas de efetivar uma reinserção social e com um reforço continuadamente maior de permanência no hospital, gerando um círculo perverso de reclusão e isolamento que incide diretamente em sua afetividade, entrecruzando as duas dimensões até aqui aprofundadas. ${ }^{15}$

Chama a atenção o intenso processo de perdas que 0 paciente vivencia, segundo a estrutura representacional dos profissionais de saúde mental, que engloba especialmente aquela ligada à própria identidade, com destaque também, ainda que em menor importância, do seu espaço de vivência, experiência, atividade e locomoção. Ressalta-se, ainda, que em instituições totais como nos hospitais em que se realizou esta pesquisa, existem dispositivos de apagamento das diferenças individuais, bem como a perda das relações e objetos que compuseram a história pessoal de cada interno, num processo conhecido como desindividualização ou despersonalização, ${ }^{15-18}$ levando a anomia. Neste, percebe-se o entrecruzamento das dimensões da exclusão e da afetividade, normalmente em um processo de potencialização de ambas no universo cotidiano dos pacientes.

A dimensão assistencial da representação refere-se ao processo de permanência (crônico) e até mesmo de morte (esta última, pela própria palavra) no núcleo central em um contexto institucional que se destaca pela presença dos léxicos institucionalização, entre os elementos de contraste, e hospital, na segunda periferia. Ressalta-se que, em que pese a baixa frequência atribuída à palavra institucional, citada apenas duas vezes, ela o foi sempre na primeira posição e, portanto, apresentou um rang equivalente a 1,00, o menor da análise.

Ainda entre os elementos da segunda periferia, podese observar a presença de cuidado que também se apresenta como elemento positivo em uma representação, como já pontuada, caracteristicamente negativa. 0 cuidado parece refletir o processo chave implementado pelos profissionais em seus cotidianos assistenciais, tanto no que se refere às demandas objetivas do processo saúde doença dos pacientes, quanto ao atendimento das demandas de subjetividade, como a afetividade, fortemente presente na estrutura desta representação.

0 cuidado neste contexto, ou seja, o cuidado em saúde mental possui como pressuposto teórico os princípios da integralidade, devendo assistir ao ser humano em todas as áreas bio-psico-sócio-espirituais, não fragmentando a ação. Cuidar é um ato complexo que exige, do profissional, conhecimento, empatia e sensibilidade. Nele também estão incluídas tarefas como tocar, sentir, escutar e auxiliar o outro nas atividades em que ele apresenta dificuldade. ${ }^{15}$ Para a existência de cuidado humanizado, é necessário ocorrer empatia, afetividade, envolvimento e aproximação entre 0 profissional e aquele que é cuidado com finalidade terapêutica, não limitando o cuidar apenas às características das técnicas. 0 cuidar em saúde mental, especificamente em uma perspectiva psicossocial, deve estar alicerçado nos pressupostos da Reforma Psiquiátrica, que, por sua vez, pode ser compreendida como um movimento de transformações das práticas, saberes, valores culturais e sociais. ${ }^{15}$

Torna-se importante aprofundar, mesmo que parcialmente, a presença da palavra crônico, como uma possível cognição central desta representação. Assim sendo, a representação pode englobá-la de forma tão importante, não somente como resultante dos longos anos de internação vivenciados pelos pacientes, mas também como produto das propostas assistenciais ofertadas a essa clientela ao longo dos anos através de políticas e programas de saúde que foram implementados pelos sujeitos deste estudo. 
No início do século XX, os pacientes psiquiátricos crônicos eram um grande desafio para as propostas assistenciais da época, como destacam vários autores, inclusive alguns que abordam a saúde mental no Brasil. ${ }^{5-15}$ Como tentativa de solucionar esse problema foram criadas, na década de 20, as Colônias de Alienados do Engenho de Dentro e a Colônia de Alienados de Jacarepaguá. A ideia central, norteadora de propostas ousadas à época, balizavase em manter o paciente psiquiátrico em locais dotados de extensas áreas verdes e distantes dos centros urbanos, nos quais a sua presença era pouco aceita. Durante décadas, 0 lema praxis omnia vincit (a prática sempre vence) forneceu a direção para a assistência, traduzindo o caráter futurista no qual a o trabalho nos campos das colônias era uma alternativa para o confinamento dos doentes em hospitais fechados.

Neste contexto, classifica-se o paciente psiquiátrico crônico como aquele sujeito que possui, em função dos longos períodos de internação e da gravidade da patologia, capacidades funcionais sobre três ou mais aspectos primários da vida diária, como o autocuidado, a autonomia, as relações interpessoais, o trabalho e a aprendizagem, necessitando de atenção hospitalar ou de tratamento psiquiátrico prolongados, o que, por sua vez, dificulta, de modo crescente e contínuo, o desenvolvimento de sua própria autossuficiência econômica. Cuidar de pacientes psiquiátricos crônicos é um trabalho complexo devido às peculiaridades apresentadas pelo próprio sujeito, pela instituição e pela equipe interdisciplinar. ${ }^{4-6-15}$

No que tange ao núcleo central desta representação, a presença da morte revela a síntese da sua negatividade, já que ela ocorre como fruto de um processo de exclusão e de perda de identidade, em um contexto fortemente institucionalizado. Pode-se encontrar, na fala dos entrevistados, a justificativa para essa evocação, ora ligada à finitude de uma vida carregada de dor, sofrimento e perdas, ora como a expressão da única possibilidade vislumbrada pelo profissional para esses pacientes. Assim, os sujeitos ainda afirmam que o envelhecimento nesse contexto liga-se à morte social, que não expressa o fim da vida biológica, mas implica um tipo de ausência do contexto social, familiar e intersubjetivo que indica a sua não existência para possíveis grupos de referência. ${ }^{15}$

Encontra-se, ainda, no seio da estrutura representacional, uma dimensão que inclui um processo avaliativo acerca deste envelhecimento que comporta, em si, três léxicos, quais sejam, enlouquecedor, ruim e difícil. Como os demais elementos da representação social, esta dimensão mostra-se basicamente negativa, atribuindo ao objeto uma apropriação particular do fenômeno estudado para os profissionais que vivenciam este envelhecer em um contexto institucional e asilar.

\section{CONCLUSÕES}

Através deste estudo, verificou-se que os conteúdos e a estrutura representacional acerca do processo de envelhecimento em psiquiatria mostrou-se essencialmente negativa, possivelmente fruto de uma realidade multifacetada, na qual se misturam o abandono familiar, a exclusão social, 0 isolamento social, o sucateamento progressivo do sistema de saúde, as dificuldades da formação profissional, a característica moderna de valorização da razão e do lucro em detrimento do humano. Essa negatividade, entre outras coisas, também resulta de construções representacionais acerca da loucura e do louco hegemônicas na sociedade capitalista. Esta negatividade possui tamanha intensidade que se desdobra em todas as dimensões da análise, inclusive em sua explicitação na, ainda, dimensão inicial de avaliação.

Este estudo evidenciou um forte processo de desfiliação social, na qual a perda de referências grupais e identitárias caracterizam o envelhecimento no contexto asilar psiquiátrico, pelo menos nos cenários estudados. Neste momento, torna-se importante destacar a importância que essas representações podem ter na concretização dos cuidados em saúde, articulando-os com as dificuldades que se observam no cotidiano das instituições. Para isso, apresenta-se como premente o desenvolvimento de outros estudos que apreendam a relação desta representação com as práticas profissionais e institucionais, em distintos hospitais psiquiátricos.

As dimensões presentes na estrutura da representação mostram como o grupo de profissionais estudados organiza a reconstrução sociocognitiva do processo de envelhecimento no contexto institucional psiquiátrico, com dimensões que fornecem sentido, inclusive à prática profissional, e determinam, em diversas situações, a adoção de determinadas atitudes e/ou ações. Neste sentido, conhecer as representações sociais dos profissionais possibilita à enfermagem um instrumental a mais para planejar e empreender mudanças no contexto assistencial.

Salientamos que, dada à complexidade da temática, não pretendemos esgotá-la nesta discussão. Estudos sobre pacientes que envelheceram em instituições com características asilares na área de saúde mental/psiquiatria são escassos, possivelmente, em face da complexidade que os mesmos envolvem. Vale frisar que, no ano de 2011, completar-se-ão 10 anos da promulgação da Lei 10.116/ $01^{9}$ que exigiu o fechamento dos hospitais psiquiátricos e criação de uma rede de serviços substitutivos.

Contudo, verificou-se através deste estudo um quantitativo significativo de sujeitos que envelheceram e permanecem internados nesses hospitais, contrariando as proposições da legislação nacional. 


\section{REFERÊNCIAS}

1.Organización Mundial de la Salud- OMS. Envejecimiento y urbanización globales: afrontando el desafío del éxito de la humanidad. Ciudades globales amigables con los mayores : una guía. 2007; 1 (1) 08-09.

2.Instituto Brasileiro de Geografia e Estatística- IBGE. Perfil dos idosos responsáveis pelos domicílios. Censo Demográfico. 2003; 1 (1) 54.

3.Lei.$^{0} 10.741$, de $1^{\circ}$ de outubro de 2003. Estatuto do Idoso. [on-line] 2003; [citado 2010 maio 01] 1 (1): 7-68. Disponível em: http:// www.planalto.gov.br/ccivil/leis/2003/L10.741.htm.

4.Pollo SHL, Assis M. Instituições de Longa Permanência para Idosos - ILPIS: desafios e alternativas no município do Rio de Janeiro. Rev Bras Geriatr Gerontol. [on-line] 2008 jan [citado 2010 mar 15]; 11 (1): [aprox. 6 telas]. Disponível em: http://www.unati.uerj.br/tse/ scielo.php?script=sci_arttext\&pid=s 1809 98232008000100004\&lng=pt\&nrm $=$ iso

5.Amarante PDC. O homem e a serpente: outras histórias para a loucura e a psiquiatria. Rio de Janeiro(RJ): Fiocruz; 1996.

6.Azevedo DM, Miranda FAN, Gaudêncio MMP. Percepções de familiares sobre o portador de sofrimento psíquico institucionalizado. Esc Anna Nery. [on-line] 2009 set [citado 2010 maio 01] ; 13(3): 485-491.Disponível em: http:// www.revenf.bvs.br/scielo.php?script=sci_arttext\&pid=S1414$81452009000300005 \&$ lng $=$ pt.

7.Ministério da Saúde (Br). Saúde Mental em dados 3-PNASH. [on-line] 2006 dez [citado 2010 maio 01]; 1 (3): 13-16. Disponível em: http:// www.ccs.saude.gov.br/saudemental/pdfs/2006_SMD_03.pdf

8.Secretaria Municipal de Saúde(RJ). Sistema de Informações em Saúde Mental. [on-line]. Rio de Janeiro(R): Coordenação de Saúde Mental. [citado 2010 mar 6]. Disponível em: www.saude.rio.rj.gov.br/sisme/relatorios.

9.Lei n. 10.216, de 6 de abril de 2001. Dispõe sobre a proteção e os direitos das pessoas portadoras de transtornos mentais e redireciona 0 modelo assistencial em saúde mental. Diário Oficial [da] República Federativa do Brasil, Poder Executivo, Brasília (DF), 09 abr 2001: Seção1: 2.

10.Castel RA. As metamorfoses da questão social: uma crônica do salário. $7^{\mathrm{a}}$ ed. Petrópolis (RJ): Vozes; 2007.

11.Sá CP. Núcleo central das representações sociais. Petrópolis (RJ): Vozes; 1996.

12.Abric JC. A zona muda das representações sociais. In: Oliveira DC, organizadora. Representações sociais: uma teoria sem fronteiras. Rio de Janeiro(RJ): Museu da República; 2005. p. 23-34.

13.Campos PHF, Rouquette ML. Abordagem estrutural e componetes afetivos das representações sociais. Psic. Ref. Crít. [on-line]. $2003 \mathrm{dez}$ [citado 2010 abril 19]; 16(3): 435-45. Disponível em: http://www.scielo.br/ pdf/prc/v16n3/v16n3a03.pdf.
14.Gomes AMT, Oliveira DC. A estrutura representacional de enfermeiros acerca da enfermagem: novos momentos e antigos desafios. Rev Enferm UERJ. [on-line]. 2007 abr/jun [citado 2010 março 25]; 15(2): 168-75. Disponível em: http://www.facenf.uerj.br/v15n2/v15n2a03.pdf

15.Lougon M. Psiquiatria institucional: do hospício à reforma psiquiátrica. Rio de Janeiro (RJ): Fiocruz; 2006.

16.0liveira DC, Gomes AMT, Acioli S, Sá CP. O Sistema Único de Saúde na cartografia mental de profissionais de saúde. Texto @Contexto Enferm. [periódico na Internet]. 2007 set [citado 2010 maio 01]; 16(3): 377-86. Disponível em: http://www.scielo.br/ scielo.php?script =sci_arttext $\&$ pid $=$ S0 104 $07072007000300002 \&$ lng $=$ pt.

17.Vergès P. Appoche du noyau central: proprietès quantitatives et structurales. In: Guimelli C, organizador. Textes de base in sciences sociales: structures et transformation des représentations sociales. Paris (PA): Delachaux et Niestlé; 1994. p.233-53.

18.Pereira JAP. Nise da Silveira: imagens do inconsciente entre psicologia, arte e política. Estududos Avançados. [on-line]. 2003 set [citado 2010 maio 01]; 17(49): 197-208. Disponível em: http://www.scielo.br/pdf/ea/ v17n49/18404.pdf. 